\title{
Adding exogenous biglycan or decorin improves tendon formation for equine peritenon and tendon proper cells in vitro
}

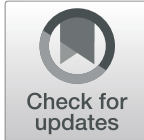

\author{
Monica Y. Pechanec ${ }^{1}$, Tannah N. Boyd ${ }^{1}$, Keith Baar ${ }^{2,3}$ and Michael J. Mienaltowski ${ }^{1 *}$
}

\begin{abstract}
Background: Tendon injuries amount to one of the leading causes of career-ending injuries in horses due to the inability for tendon to completely repair and the high reinjury potential. As a result, novel therapeutics are necessary to improve repair with the goal of decreasing leg lameness and potential reinjury. Small leucine-rich repeat proteoglycans (SLRPs), a class of regulatory molecules responsible for collagen organization and maturation, may be one such therapeutic to improve tendon repair. Before SLRP supplementation can occur in vivo, proper evaluation of the effect of these molecules in vitro needs to be assessed. The objective of this study was to evaluate the effectiveness of purified bovine biglycan or decorin on tendon proper and peritenon cell populations in three-dimensional tendon constructs.
\end{abstract}

Methods: Equine tendon proper or peritenon cell seeded fibrin three-dimensional constructs were supplemented with biglycan or decorin at two concentrations ( $5 \mathrm{nM}$ or $25 \mathrm{nM}$ ). The functionality and ultrastructural morphology of the constructs were assessed using biomechanics, collagen content analysis, transmission electron microscopy (TEM), and gene expression by real time - quantitative polymerase chain reaction (RT-qPCR).

Results: SLRP supplementation affected both tendon proper and peritenon cells-seeded constructs. With additional SLRPs, material and tensile properties of constructs strengthened, though ultrastructural analyses indicated production of similar-sized or smaller fibrils. Overall expression of tendon markers was bolstered more in peritenon cells supplemented with either SLRP, while supplementation of SLRPs to TP cell-derived constructs demonstrated fewer changes in tendon and extracellular matrix markers. Moreover, relative to non-supplemented tendon proper cell-seeded constructs, SLRP supplementation of the peritenon cells showed increases in mechanical strength, material properties, and collagen content.

Conclusions: The SLRP-supplemented peritenon cells produced constructs with greater mechanical and material properties than tendon proper seeded constructs, as well as increased expression of matrix assembly molecules. These findings provide evidence that SLRPs should be further investigated for their potential to improve tendon formation in engineered grafts or post-injury.

Keywords: Equine, Tendon, Peritenon, Biglycan, Decorin, Three-dimensional construct

\footnotetext{
* Correspondence: mjmienaltowski@ucdavis.edu

'Department of Animal Science, University of California Davis, 2251 Meyer

Hall, One Shields Ave, Davis, CA 95616, USA

Full list of author information is available at the end of the article
}

(c) The Author(s). 2020 Open Access This article is licensed under a Creative Commons Attribution 4.0 International License, which permits use, sharing, adaptation, distribution and reproduction in any medium or format, as long as you give appropriate credit to the original author(s) and the source, provide a link to the Creative Commons licence, and indicate if changes were made. The images or other third party material in this article are included in the article's Creative Commons licence, unless indicated otherwise in a credit line to the material. If material is not included in the article's Creative Commons licence and your intended use is not permitted by statutory regulation or exceeds the permitted use, you will need to obtain permission directly from the copyright holder. To view a copy of this licence, visit http://creativecommons.org/licenses/by/4.0/ The Creative Commons Public Domain Dedication waiver (http://creativecommons.org/publicdomain/zero/1.0/) applies to the data made available in this article, unless otherwise stated in a credit line to the data. 


\section{Background}

Tendinopathies like those of the superficial digital flexor tendon (SDFT) result in major leg lameness and are debilitating for horses of all disciplines [1, 2]. For both acute and chronic tendinopathies, like those of the SDFT, a closer look at the pathology associated with tendon injury oftentimes implicates alterations in extracellular matrix (ECM) regulators of collagen fibrillogenesis and organization [3]. Alterations in the expression of ECM regulators lead to changes in biomechanical properties that impact the strength and stability of these energy storing tendons [4]. Due to this, novel therapeutics are necessary since complete repair is unlikely and further injury is a major concern $[2,3]$.

Small leucine-rich repeat proteoglycans (SLRPs) are a class of regulatory molecules that are essential for collagen organization in tendon development, maturation, and repair [5]. The contributions of SLRPs have been particularly well-characterized in tendons [6-12]. Besides directly affecting collagen fibrillogenesis, SLRPs like biglycan (BGN) and decorin (DCN) play roles in determining how tissue niche impacts cell biology, including: 1) the differentiation status of tendon progenitors in health and pathology [13]; 2) inflammatory regulation as Damage Associated Molecular Pattern proteins interacting with Toll-like receptors [14]; 3) recruitment of cells to sites of tissue repair or regeneration [15]; and 4) sequestration of growth factors essential for generation and maintenance of the tendon phenotype [13]. Previous work has demonstrated that the absence of these SLRPs dramatically affects tendon repair outcomes with BGN essential early in repair and DCN crucial later in tendon repair [7, 9]. Interestingly, expression of $B G N$ and $D C N$ in mature animals decreases after an injury and never recovers to the level seen during development and maturation [11], suggesting that low BGN and/or DCN may contribute to the impaired injury response.

After a mature tendon is injured, repair occurs as a result of extrinsic and intrinsic influences. Leukocytes and fibroblasts migrate into the lesion early in repair [15]. Post-injury, these fibroblasts originate from the extrinsic paratenon and have demonstrated distinct differences in marker expression and tenogenic potential as compared to the tendon proper fibroblast cell population [16-20]. Thus, when considering therapeutic interventions for tendon repair, both cell populations should be included since the role of each cell type remains unresolved.

Recognizing the value of BGN and DCN in tendon development and maturation and their subsequent decline at the time of repair, we hypothesize that addition of BGN or DCN to the tendon matrix would improve tendon formation. To test this hypothesis, equine tendon proper (TP) and peritenon (PERI) cells were seeded in an in vitro fibrin-based three-dimensional tendon construct model in which the gel contained two differing amounts of either exogenous bovine purified BGN or exogenous bovine purified DCN. The effects of the exogenous BGN or DCN on biomechanics, electron microscopic ultrastructure, collagen content, and gene expression were determined.

\section{Methods}

\section{Tendon harvest and cell isolation}

Equine superficial digital flexor tendon (SDFT) cells were harvested from five horses of various breeds (ages 8-15 years) with approval from the University of California Davis Institutional Animal Care and Use Committee. All horses were property of the University of California Davis and were assessed as healthy with no known tendinopathies and were euthanized by intravenous injection of euthanasia solution (pentobarbital sodium and phenytoin sodium) for reasons unrelated to the study. After euthanasia, $2.5 \mathrm{~cm}$ of forelimb SDFT was harvested per horse approximately $10-15 \mathrm{~cm}$ proximal of the forelimb fetlock. Tendons were transported to the lab in Dulbecco's Phosphate Buffer Solution (DPBS, Life Technologies, Benicia, CA, USA) containing 1\% antibiotic/ antimycotic $(10,000$ units $/ \mathrm{mL}$ penicillin, $10,000 \mu \mathrm{g} / \mathrm{mL}$ streptomycin, and $25 \mu \mathrm{g} / \mathrm{mL}$ amphotericin B, Life Technologies). For each horse, tissue from the tendon proper and peritenon regions were isolated while submerged in DPBS containing 1\% antibiotic/antimycotic. Under a dissecting microscope and sterile conditions, the peritenon region was isolated by removing the paratenon and 1 $\mathrm{mm}$ of the epitenon region using forceps and sterile scalpel blades. The tendon proper region of the tendon was isolated by removing a $2 \mathrm{~mm}$ square the length of the sample of the tendon core $[5,18,20]$. Separated regions were then used for digestion to isolate the different cell populations for each horse. Enzymatic digestion followed previous protocols using $0.3 \%$ type-I collagenase (CLS-1, Worthington, Lakewood, New Jersey, USA) and $0.4 \%$ Dispase II (Roche, Basel, $\mathrm{CH}$ ) in Hanks Balanced Salt Solution (HBSS, Gibco, Benicia, CA, USA) with enzymatic inactivation after agitation in standard tenocyte media (alpha-MEM, 10\% fetal bovine serum, 2 mM L-glutamine, and $1 \%$ antibiotic/antimycotic) [20, 21]. Cells from each region for each horse were plated in T75 flasks and expanded in standard tenocyte media. Cells from each region for each horse were passaged before being cryopreserved in 10\% dimethyl-sulfoxide (DMSO) solution in standard tenocyte culture media under liquid nitrogen after reaching P2.

To make constructs, frozen vials of peritenon and tendon-proper cells were thawed and seeded as P3 in T75 flasks at 6666 cells per $\mathrm{cm}^{2}$ and grown to $85 \%$ confluency in normal tenocyte media. Tear-drop shaped brushite anchors (100 mM citric acid and $3.5 \mathrm{M}$ 
orthophosphoric acid added to dense $\beta$-tricalcium phosphate mixture ( $\beta$-TCP; Plasma Biotal Limited, Derbyshire, UK) in a $1 \mathrm{~mL}$ per $1 \mathrm{~g}$ ratio) were pinned $1 \mathrm{~cm}$ apart in $35 \mathrm{~mm}$ tissue culture treated dishes cured with $3 \mathrm{~mL}$ of Sylgard (184 Silicone Elastomer Kit, Dow Corning, Midland, MI) [21-23]. For each horse sample and treatment, a minimum of 3 constructs were used for biomechanics and subsequent collagen analysis, 1 for real time quantitative polymerase chain reaction (RT-qPCR), and 1 for transmission electron microscopy (TEM). Bovine biglycan (bBGN) (Sigma-Aldrich) or bovine decorin (bDCN) (Sigma-Aldrich) was supplemented into the fibrin gel mixture at high $(25 \mathrm{nM})$ or low $(5 \mathrm{nM})$ concentrations - doses that were previously investigated with cultured myotubules, cardiomyocytes, and type I collagen gels [24-26]. Therefore, at least 50 constructs were made for each horse in order to provide a minimum of 5 technical replicates for the control, high and low bBGN, and high and low bDCN conditions for both the peritenon and tendon proper cells. To make the tendons, cells were combined with the fibrinogen-thrombin matrix gel (681 $\mu \mathrm{l}$ cell suspension with supplementation or control media, $286 \mu \mathrm{l}$ of $20 \mathrm{mg} / \mathrm{mL}$ fibrinogen, and $29 \mu \mathrm{l}$ of 200 $\mathrm{U} / \mathrm{mL}$ thrombin to get $998 \mu \mathrm{l}$ total gel volume) at 300 , 000 cells per construct and seeded in a spread method around the anchors [21]. The suspension was allowed to gel for $15 \mathrm{~min}$ before adding tenocyte standard media supplemented with $200 \mathrm{uM}$ ascorbic-2-phosphate into the wells [20]. Constructs were maintained at $37^{\circ} \mathrm{C}$ in $5 \% \mathrm{CO}_{2}$ for 14 days with media changes every $2-3$ days.

\section{Biomechanical testing}

At day 14, length and width of a minimum of 3 constructs for each treatment was determined using digital calipers before being loaded into a horizontal uniaxial tensile testing machine within a saline bath [27-29]. Samples were tested to failure without preconditioning at a constant displacement rate of $0.4 \mathrm{~mm} / \mathrm{s}$ [30]. LabVIEW (National Instruments, Austin, TX) software recorded the resulting force measurements and the loaddeformation curve was used to determine the maximal tensile load (MTL) of the construct. The load and deformation values were normalized to the cross-sectional area (CSA) and initial construct length, respectively, to calculate stress and strain. The ultimate tensile stress (UTS) was recorded as the highest stress value before failure, whereas Young's modulus was determined by calculating the slope of the linear portion of the stressstrain curve.

\section{Collagen content}

Following biomechanical testing, constructs were removed from anchors, patted dry, and placed on glass to dehydrate at $120^{\circ} \mathrm{C}$ for 20 mins. Dried constructs were weighed and either stored in individual tubes until necessary or immediately processed for hydroxyproline analysis. Analysis followed a previously described protocol using $6 \mathrm{~N}$ hydrochloric acid at $120^{\circ} \mathrm{C}$ for $2 \mathrm{~h}$ for hydrolysis, followed by $1.5 \mathrm{~h}$ to evaporate the hydrochloric acid. Hydroxyproline buffer (3.3\% citric acid, $2.3 \%$ sodium hydroxide, $0.8 \%$ acetic acid in water, $\mathrm{pH} 6.0-6.5$ ) was used to resuspend the pellets and resulting solution was stored in $-20^{\circ} \mathrm{C}$ until further processing [27]. Stock samples were diluted to 9:1 or 4:1 hydroxyproline buffer: stock sample to allow for more accurate colorimetric detection. Chloramine-T $(14.1 \mathrm{mg} / \mathrm{mL})$ and aldehyde perchlorate solution were added in a step-wise fashion to each diluted sample before heating, cooling, and reading the samples and standards in a UV spectrophotometer at $550 \mathrm{~nm}$ [31-34].

\section{Transmission Electron microscopy}

At day 14, constructs were rinsed with phosphate buffer solution (PBS) and fixed at length by complete immersion in Karnovsky's fixative for $2 \mathrm{~h}$ at $4{ }^{\circ} \mathrm{C}$ then stored in transport solution for up to 1 week before embedding. Further processing of constructs for TEM followed previously described protocols $[10,18,29-31$, $35,36]$. Briefly, fresh epoxy resin was used to embed constructs cut in thirds cross-sectionally and polymerized for $12 \mathrm{~h}$ at $60^{\circ} \mathrm{C}$ (EMBed - 812, Electron Microscopy Sciences, Hatfield, PA, USA). Blocks sectioned at $70 \mathrm{~nm}$ by ultramicrotome were post-stained with $2 \%$ aqueous uranyl acetate and 1\% phosphotungstic acid, pH 3.2 [20]. Images were taken at $80 \mathrm{kV}$ using a FEI C120 transmission electron microscope (FEI Co, Hillsboro, OR) with a Gatan Orius CC Digital camera (Gatan Inc., Pleasanton, CA). All images used for fibril diameter analysis, fibril density, collagen organization, and structure were taken at 33,000x. Fibril diameter distribution was visualized using ImageJ software (National Institutes of Health, Bethesda, MD) and means were calculated from 5 images per testing group within each biological sample with no more than 100 fibrils per image counted for a total of 500 fibril diameters per biological sample. Fibril density and fibrils per area of extracellular matrix $(E C M)$ per image were calculated using the same $5 \mathrm{im}$ ages as the fibril diameters.

\section{Total RNA isolation and real time quantitative PCR (RT- qPCR)}

At day 14, constructs were snap frozen in liquid nitrogen and stored at $-80^{\circ} \mathrm{C}$ until further processed. Homogenization of the tendon constructs was done using a BioSpec Tissue-Tearor and total RNA isolation was performed using the RNeasy Plus Micro Kit (QIAG EN, Valencia, CA) including a RNase-free DNase treatment (QIAGEN, Valencia, CA). Reverse transcription 
was performed on $500 \mathrm{ng}$ total RNA using a High Capacity cDNA Reverse Transcription Kit (Life Technologies). Genes assessed included tenogenic differentiation $(M K X$, $F M O D)$, ECM assembly (BGN, DCN, COL1A1, LOX), or perivascular (CSPG4) markers [7, 18, 20, 37, 38]. POLR2A was used as the housekeeping gene [19, 37, 39]. Taqman primers were designed from equine gene structure annotation (NCBI Equicab 3.0) using Primer3 or from predesigned primers (Life Technologies) (Table S-1) [40, 41]. For RT-qPCR analysis, 1 ul of cDNA template was combined with Taqman Master Mix (no UNG) (Life Technologies) and equine specific primers for a reaction volume of $20 \mathrm{ul}$ in a StepOnePlus Real-Time PCR System (Applied Biosystems, Foster City, CA) [19]. Each sample of amplified cDNA was analyzed in duplicate for each gene with gene specific efficiencies calculated using LinRegPCR v 7.5 software $[7,18,19]$. The relative quantity ratios formula was used to calculate the relative quantity of mRNA for each gene $[42,43]$.

\section{Statistics}

GraphPad Prism (GraphPad Software, Inc., San Diego, CA) was used for all statistical analyses. Mean values for technical replicates within biological replicates were calculated before differences of the mean values were compared within testing categories to avoid pseudoreplicates. Statistical analyses were all performed using nonparametric Wilcoxon signed-rank tests in which each treatment ( $5 \mathrm{nM}$ bBGN, $25 \mathrm{nM}$ bBGN, $5 \mathrm{nM}$ bDCN, $25 \mathrm{nM}$ bDCN) was compared to its corresponding control with a one-sided test applied [44-46]. The $\mathrm{H}_{0}$ was that the addition of SLRPs to the constructs would lead to no improvement or a decline in tenogenic features; the $\mathrm{H}_{\mathrm{a}}$ was that the addition of SLRPs would improve tenogenic properties, or promote tendon formation, as described in several studies: (1) increased UTS, Young's modulus, and MTL; (2) increased collagen content; (3) increases in collagen fibril numbers with increases in fibril diameters; (4) increased relative expression of tendon markers $S C X$ and $M K X$, (5) increased expression of ECM assembly markers; and (6) decreased expression of perivascular markers $[6-10,12$, 17-22, 27]. Significance level was set at $p \leq 0.05$. Given the limited "n," wherever analyses approached significance with $p=0.0625$ (i.e., measurement ranks switched within one pair of the samples), it was noted in the results.

\section{Results}

\section{Biomechanics and collagen content}

Constructs contracted successfully and were assessed at 14 days post seeding with cells aligned unilaterally and no qualitative differences seen between peritenon and tendon proper cells upon gross microscopic examination. The supplementation of SLRPs bBGN and bDCN improved biomechanics in many instances (Fig. 1). Peritenon cells supplemented with $25 \mathrm{nM}$ bBGN showed significantly increases in UTS $(p=$ $0.0313)$ and Young's modulus $(p=0.0313)$. Increases in UTS approached significance $(p=0.0625)$ when PERI cells were supplemented with $5 \mathrm{nM}$ or $25 \mathrm{nM}$ bDCN. Increases in Young's modulus approached significance $(p=0.0625)$ when PERI cells were supplemented with $5 \mathrm{nM}$ bBGN, $5 \mathrm{nM}$ bDCN, or $25 \mathrm{nM}$ bDCN. For tendon proper cells, Young's modulus significantly increased for constructs supplemented with $25 \mathrm{nM}$ bDCN $(p=0.0313)$. Otherwise, for TP cells, increases in Young's modulus approached significance $(p=0.0625)$ when supplemented with $5 \mathrm{nM}$ bBGN or $5 \mathrm{nM}$ bDCN. No significant increases in CSA were seen when TP or PERI cells were supplemented with bBGN or bDCN.

SLRP-treated PERI cell constructs were compared to TP cell control constructs in regard to biomechanics to discern if SLRP-supplemented PERI cells created biomechanically superior constructs (Fig. S-1). UTS was significantly greater for PERI constructs supplemented with $25 \mathrm{nM}$ bBGN. Relative to TP cell control constructs, Young's modulus was significantly greater for PERI cells supplemented with $25 \mathrm{nM}$ bBGN or $5 \mathrm{nM}$ bDCN, and MTL was greater for PERI cell constructs receiving 5 $\mathrm{nM}$ bBGN or $25 \mathrm{nM}$ bDCN.

Increases in collagen content approached significance $(p=0.0625)$ in TP and PERI constructs supplemented with $25 \mathrm{nM}$ bDCN (Fig. 2a). For collagen content as a fraction of dry mass (\%), neither tendon proper nor peritenon cells showed improvement with any supplementation (Fig. 2b). Likewise, when comparing SLRP-treated PERI cell constructs with TP cell control constructs, supplementation with $25 \mathrm{nM}$ bBGN or $5 \mathrm{nM}$ bDCN increased collagen content (Fig. S-2A), yet not as a percentage of dry mass (Fig. S-2B).

\section{Transmission Electron microscopy}

TEM cross-sections were used to analyze collagen fibril diameters (Fig. S-3). Fibril analyses showed slight shifts towards smaller fibrils for PERI cells in constructs supplemented with $25 \mathrm{nM}$ bBGN, $5 \mathrm{nM}$ bDCN, and $25 \mathrm{nM}$ bDCN, as well as for TP cells in constructs supplemented with $5 \mathrm{nM}$ bBGN, $5 \mathrm{nM}$ bDCN, and $25 \mathrm{nM}$ bDCN (Fig. 3). A bimodal distribution can be seen for TP cell-derived constructs with $25 \mathrm{nM}$ bBGN supplementation. When comparing mean fibril diameter (nm) of SLRP-supplemented constructs with their respective controls, though not statistically significant, mean diameters of PERI constructs were roughly the same size, and mean diameters of TP constructs were slightly smaller or the same size. For normalized fibrils per area of 
A



C

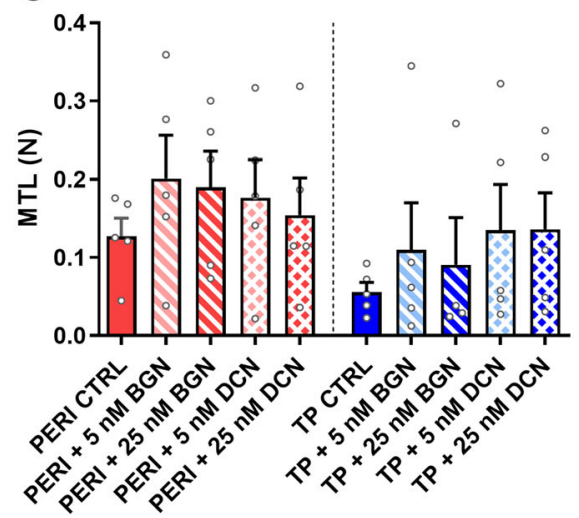

B

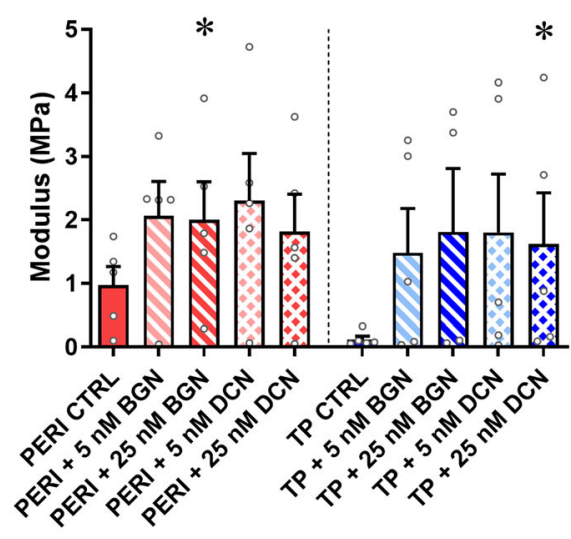

D

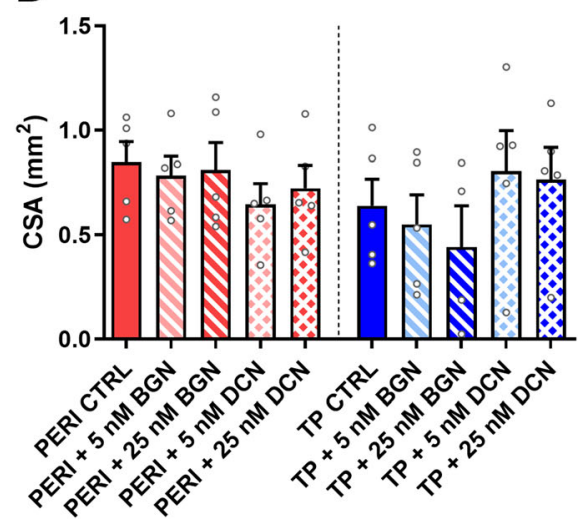

Fig. 1 Biomechanical properties for 5 and $25 \mathrm{nM}$ purified bBGN or bDCN supplementation. a Ultimate tensile strength (UTS), b Young's modulus, and c Maximum tensile load (MTL) were measured across five biological replicates and plotted as mean + SEM. TP: tendon proper cells; PERI: peritenon cells; CTRL: no bBGN or bDCN supplementation. Significance is based on one-sided nonparametric Wilcoxon signed-rank tests predicting improvement: *, significant as $p \leq 0.05$, relative to the respective TP or PERI control; $n=5$. Outliers detected by the Grubbs' test in technical replicates (UTS, 4; Young's modulus, 3; MTL, 2; CSA, 1; $p<0.05)$ were removed

extracellular area, no significant differences were found (Fig. 4).

To understand how SLRP-treated PERI cell constructs compared to TP cell control constructs, fibril diameter distribution analyses demonstrated relative shift towards larger fibrils (Fig. S-4) and trends of more fibrils with more fibrils per area of ECM (Fig. S-5) when supplemented with bBGN and bDCN.

\section{Gene expression}

Gene expression analyses informed how SLRP supplementation within the constructs affected TP and PERI cell tenogenic properties (Fig. 5). When PERI cells in constructs were supplemented with $5 \mathrm{nM}$ bBGN, increased expression of BGN, SCX, and COL1A1 approached significance $(p=0.0625)$; however, expression of CSPG4 was elevated. PERI cells supplemented with $25 \mathrm{nM}$ bBGN had increased $B G N$ and $S C X$ expression ( $p=0.0313)$. Supplementation of $5 \mathrm{nM} \mathrm{bDCN}$ led to increased expression $(p=0.0313)$ of $B G N$ and $S C X$ with an increase in COL1A1 approaching significance $(p=0.0625)$. Moreover, expression decreased for CSPG4 when PERI cells were supplemented with $5 \mathrm{nM}$ DCN $(p=0.0313)$. PERI cells supplemented with $25 \mathrm{nM}$ bDCN showed increased expression of BGN, FMOD, and $S C X$ ( $p=0.0313$ for each), and decreased expression of CSPG4 $(p=0.0313)$. Additionally, when PERI cell constructs were supplemented $25 \mathrm{nM}$ bDCN, increases in expression of $M K X, D C N$, and COL1A1 approached significance $(p=0.0625)$.

For the markers tested, overall fewer significant changes were seen in gene expression demonstrating improvements in tenogenesis for the tendon proper cellderived constructs. TP cell constructs supplemented with $5 \mathrm{nM}$ bBGN only demonstrated increased expression of $\operatorname{SCX}(p=0.0313)$; supplementation of $25 \mathrm{nM}$ 


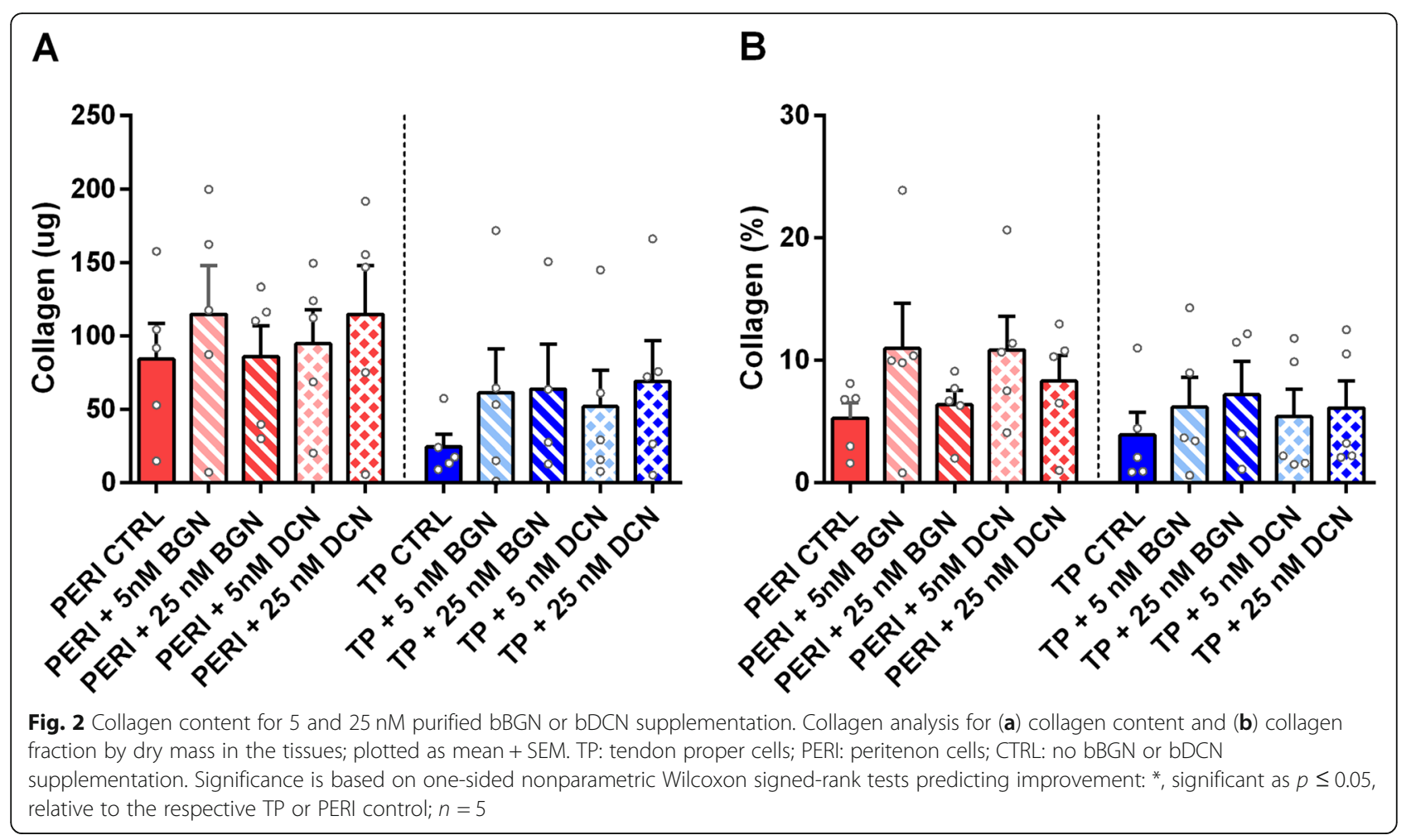

bBGN led to an increase in $B G N$ expression that only approached significance $(p=0.0625)$. No significant tenogenic improvements in expression were seen with supplementation of $5 \mathrm{nM}$ bDCN or $25 \mathrm{nM}$ bDCN.

When SLRP-treated PERI cell constructs were compared to TP cell control constructs, bBGN and bDCN PERI cell-derived constructs had similar matrix assembly marker expression levels as TP cell control constructs (Fig. S-6).

\section{Discussion}

Embedding small leucine-rich proteoglycans within a fibrin gel affected features of the engineered tendons. When considering gene expression, the supplementation






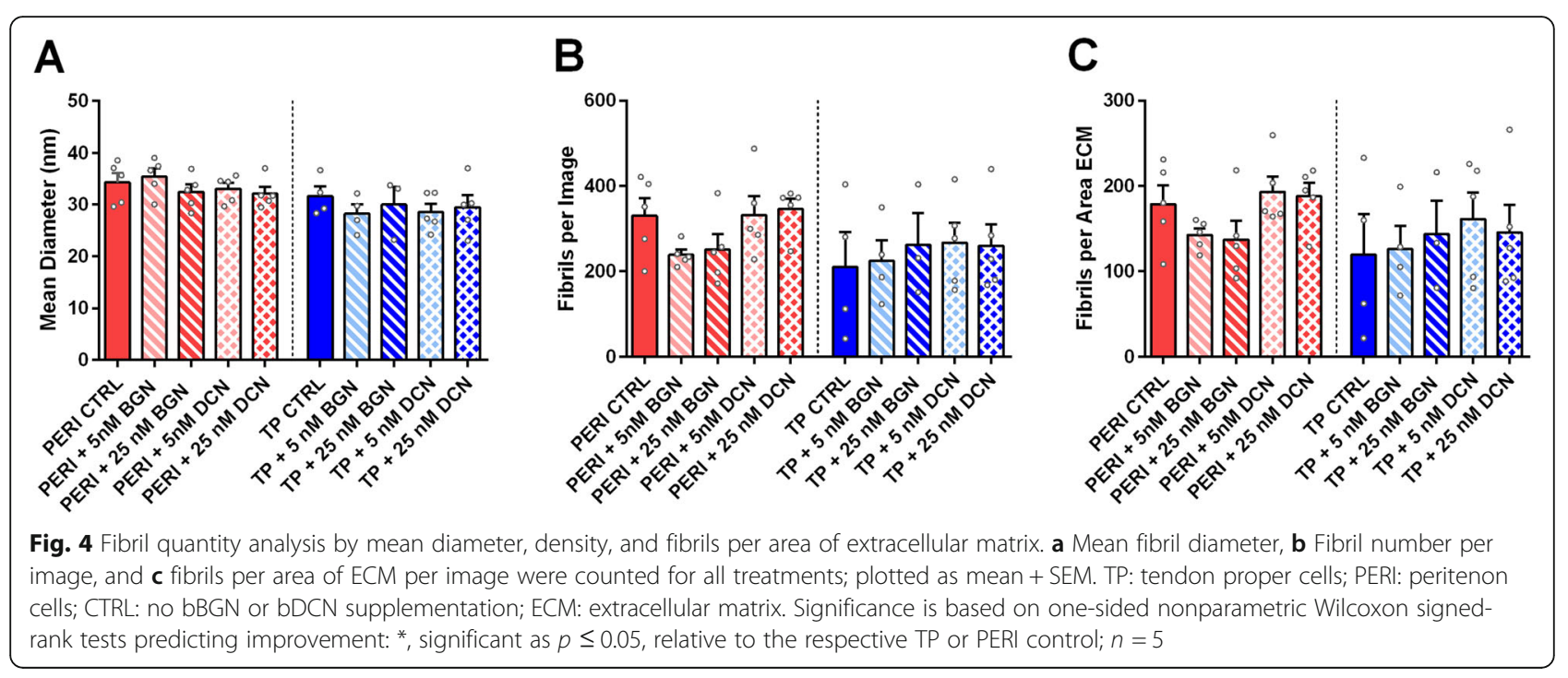

of either exogenous biglycan or decorin had a greater effect on the tenogenic capacity of the equine peritenon cells than they did on tendon proper cells. Yet, biomechanical properties were bolstered by supplementation of SLRPs for both cell types to varying degrees. PERI cells supplemented with bBGN or bDCN showed significant or approaching significant increased Young's modulus, and ultimate tensile strength in PERI cells increased with the addition of $25 \mathrm{nM}$ bBGN. Moreover, tendon proper cell-seeded constructs had increased Young's modulus for and $25 \mathrm{nM}$ bDCN, and nearly significant increases for $5 \mathrm{nM}$ bBGN and $5 \mathrm{nM}$ bDCN. These results suggest that SLRP supplementation can have positive tenogenic effects on extrinsic PERI cells and intrinsic TP cells.

Cells within a connective tissue can be affected by changes in their tissue niche. For example, if biglycan and decorin expression are absent during development the resulting changes affect the fibril structure with a shift toward larger diameters. In addition to alterations in mechanical properties, such as a failure at lower loads, decreased stiffness, and increase in percent relaxation, knocking out expression of biglycan and decorin affects collagen fiber realignment with a slower response to load [7, 9, 12]. Other knockout SLRP models, including biglycan, decorin, and double biglycan and fibromodulin, have varying degrees of apparent phenotypes including accelerated degeneration of articular cartilage, subchondral sclerosis, reduced growth rate of bone with decreased bone mass, and disruption of proper collagen fibrillogenesis [4750]. Conversely, supplementation of SLRPs provides evidence for crucial roles in: signaling pathways, such as the TGF- $\beta$ (transforming growth factor beta), WNT, TLR (toll-like receptor), EGFR (epithelial growth factor receptor) internalization, and Akt -dependant/-independent; collagenase shielding; collagen fibrillogenesis in the form of wound healing and scar mitigation; and proteoglycan regulation $[26,50-$ 59].

When evaluating gene expression of the PERI supplemented cells, $5 \mathrm{nM}$ bDCN showed significant increases in BGN, FMOD, and Scleraxis $(S C X)$ and a significant decrease in CSPG4. The increase in tendon specific markers may be the result of regulation in the TGF $\beta$ pathway with decreased activation of ERK1/2 resulting in increased expression of $S C X$ and subsequently SLRPs like $B G N$ by TGF $\beta[60,61]$. Although the cross-linking marker LOX tends to decrease, biomechanics (UTS and Young's Modulus) increase and the fibril distribution is shifted to smaller fibrils indicating that more collagen fibrils are being produced (supported by a trend towards increased COL1A1 expression) but the fibrils are not maturing and cross-linking remains low (Fig. 5, Fig. S-3). Previous studies in $D C N$ knockout mouse models identified an increase in fibril diameter with subsequent decrease in elastic and viscoelastic properties while alterations of the dermatan sulfate side chains had no effect on mechanical properties indicating that the decorin core protein itself is essential for the organization of collagen and its resulting tissue mechanics [12, 26, 47]. In contrast to DCN, the $5 \mathrm{nM}$ bBGN supplementation produced increases in CSPG4 expression, suggesting that although $B G N$ and $D C N$ have similar signaling pathways in collagen fibrillogenesis they are antagonistic in perivascularization. In breast carcinoma cells, $D C N$ had an anti-angiogenic effect while $B G N$ in bone fractures increased pro-angiogenic signals such as VEGFA (vascular epithelial growth factor A) showing that $B G N$ and $D C N$ have antagonistic effects, thus explaining the difference in CSPG4 expression between bBGN and bDCN in PERI 
Pechanec et al. BMC Musculoskeletal Disorders

(2020) 21:627

Page 8 of 11

A

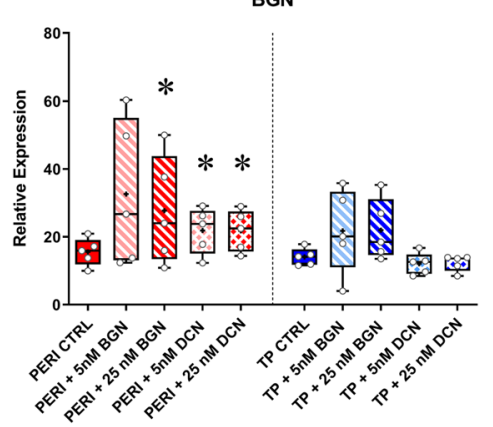

B

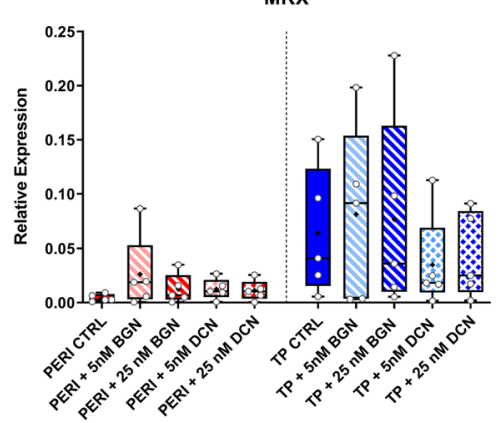

C

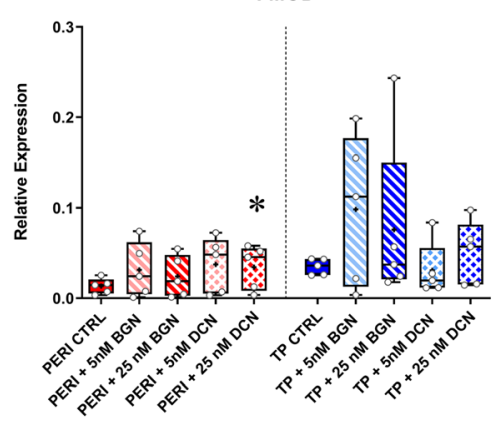

D

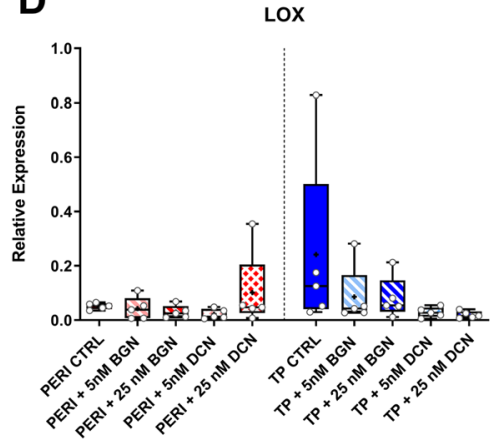

E



$\mathbf{F}$



G

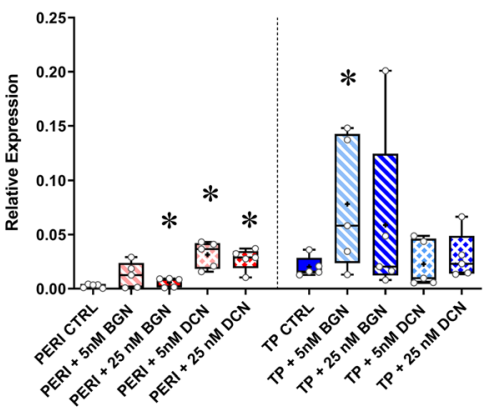

H

CSPG4

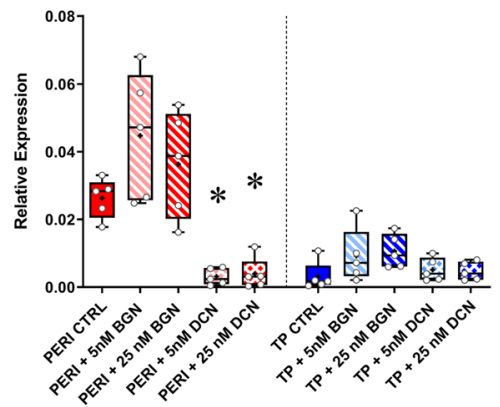

Fig. 5 (See legend on next page.) 
(See figure on previous page.)

Fig. 5 RT-qPCR analysis of perivascular and tenogenic markers. For each gene, the gene expression was plotted against the housekeeping gene POLR2A. TP: tendon proper cells; PERI: peritenon cells; CTRL: no bBGN or bDCN supplementation. Expression is plotted in a box and whisker plot with " + " representing the mean, box representing first-third quartile, line representing median, and whisker representing range. Significance is based on one-sided nonparametric Wilcoxon signed-rank tests predicting improvement: ${ }^{*}$, significant as $p \leq 0.05$, relative to the respective TP or PERI control; $n=5$

cells $[62,63]$. This would indicate that during fibrillogenesis following an injury, $D C N$ may play a vital role in mitigating scar formation by preventing vessel growth allowing improved tissue function $[64,65]$.

Tendon proper and peritenon cells responded differently to supplementation. Such variations could be due to the differences in niche composition within which these cells exist in vivo as well as differences in cell origins, both of which could affect the tenogenic capacity of these cell types [18-20,66]. The tendon proper niche consists of a stiff, relatively acellular and hypoxic environment with cells undergoing mechanical load and recoil activating characteristic signaling molecules such as $T G F \beta$ and Egrl/2 through induction of $S C X$ [67]. Other major regulators of tendon maturation and differentiation include GDF5 (growth and differentiation factor 5) and mohawk $(M K X)$ in addition to the SLRPs such as fibromodulin, and biglycan [13, 67, 68]. The peritenon niche is not as clearly defined but is comprised of cells which: (1) express perivascular markers such as endomucin (EMCN),CD34, and CD45; (2) secrete stimulatory factors during repair; (3) express matrix remodeling-related genes (matrix metalloprotease, $M M P 1$ and $M M P 3$, and COL3A1); and (4) possess high cellular phenotypic heterogeneity [18-20, 66].

Peritenon cells had a more pronounced response to SLRP supplementation, particularly for DCN. This suggests that DCN may contribute to the peritenon cells transitioning into a tendon-like phenotype after the initial inflammatory response or that DCN aids in the collagen fibril assembly in the extracellular matrix. These functions could be instrumental for tendon repair since peritenon cells are a highly mobile cell type, reacting immediately in response to an injury. Additionally, from the expression and biomechanics data, DCN supplementation could improve peritenon cell utility in engineered tendon grafts. Though tenocytes (TP cells) might seem to be good tissue engineering candidates, it is interesting to compare the response of PERI cells to SLRP supplementation relative to the non-supplemented TP control. When PERI cell-seeded constructs supplemented with SLRPs were compared to TP control constructs - tenocytes that might be used in grafts. Increases in UTS, Young's modulus, and MTL were significant or approaching significance with all four doses of SLRPs used (Fig. S-1). Relative to TP control, the constructs with PERI cells had greater collagen content or increased levels approaching significance (Fig. S-1). Moreover, PERI cell-derived constructs had similar matrix assembly marker expression levels (Fig. S-6). Although there were no differences in fibril density or mean diameter, bBGN and bDCN supplemented peritenon cells displayed a shift towards larger fibrils which partially explains the increased UTS, Young's modulus, and MTL (Fig. S-1, S-4, S5). The expression of CSPG4 in bDCN supplemented peritenon constructs was similar control TP cell-derived construct levels, which supports a shift away from a perivascular-like phenotype. This suggests the utility of DCN, in particular for peritenon cells, as a phenotype influencing signaling molecule capable of affecting cells of both regions in the tendon. This finding could have implications during injury repair and cell selection for engineered grafts. Many findings in this study support the supplementation of SLRPs like BGN and DCN in therapeutic strategies. Further studies are required to discern the exact mechanisms by which supplemental SLRPs are affecting PERI cells.

This study has a number of important limitations. First, purified bovine proteins were used with the equine cells instead of equine-derived SLRPs. Second, cellular responses to SLRP supplementation are being described in an in vitro model where the active agent is continuously present in the matrix which would not be the case in vivo in a potentially pathological or inflammatory environment. Third, construct numbers were limited, and thus extensive histological analysis, analyses of other SLRPs, and the combinatorial effects of BGN ad DCN were omitted. Fourth, the tendon cells were isolated from horses with a range of ages and breeds. Fifth, the findings are based upon cells of the equine superficial digital flexor tendon. Therefore, the results might not translate to other tendons and ligaments. Finally, a limited $n=5$ horses were used in to compare controls and treatments individually to determine if defined and hypothesized improvements in tendon formation were seen with SLRP supplementation. While this might limit the statistical power of the study, it allows for preliminary answers into the efficacy of SLRP supplementation for improving tendon formation. Moving forward, the evaluation of SLRPs in an in vivo injury model could provide further insight into this novel therapeutic intervention for injury repair for equine athletes of all disciplines. Moreover, our findings lend support to further studies that include the incorporation of SLRPs in tendon engineering strategies. 


\section{Supplementary information}

Supplementary information accompanies this paper at https://doi.org/10. 1186/s12891-020-03650-2.

\section{Additional file 1.}

\section{Abbreviations}

AKT: Protein kinase B signaling pathway; Alpha-MEM: Modified Eagle's media; BGN: Biglycan; CD34: Cluster of differentiation 34; CD45: Cluster of differentiation 45; COL1A1: Collagen, type 1, alpha 1; COL3A1: Collagen, type 3, alpha 1; CSA: Cross-sectional area; CSPG4: Chondroitin sulfate proteoglycan 4; DCN: Decorin; ECM: Extracellular matrix; EGFR: Epithelial growth factor receptor; EMCN: Endomucin; ERK: Extracellular signal-regulated kinase; FMOD: Fibromodulin; GDF5: Growth and differentiation factor 5; LOX: Lysyl oxidase; MKX: Mohawk; MMP1: Matrix metalloproteinase 1; MMP3: Matrix metalloproteinase 3; MTL: Maximum tensile load; PBS: Phosphate-buffered saline; PERI: Peritenon; POLR2A: RNA polymerase II subunit A; RT-qPCR: Real Time - quantitative polymerase chain reaction; SCX: Scleraxis; SDFT: Superficial digital flexor tendon; SLRP: Small leucine rich proteoglycan; TEM: Transmission electron microscopy; TGF- $\beta$ : Transforming growth factor $\beta$; TLR: Toll-like receptor; TP: Tendon proper; UTS: Ultimate tensile strength; WNT: Wingless and Integrator Complex Subunit 1 signaling

\section{Acknowledgements}

The authors would like to acknowledge and thank the support from the Department of Animal Science, College of Agricultural and Environmental Sciences, the Center for Equine Health of the University of California Davis, and the California Thoroughbred Foundation.

\section{Authors' contributions}

Hypothesis, experimental strategies, and experimental design originated by MJM. Cell culture, three-dimensional construct formation, RNA isolation, collagen content analysis, biomechanical analysis, and TEM preparation and imaging performed by MYP. RT-qPCR primers designed by MJM and MYP. RT-qPCR performed by TNB and MYP. Interpretation of data was done by MJM and MYP. Manuscript preparation was done primarily by MYP and secondarily by MJM and KB. The authors read and approved the final manuscript.

\section{Funding}

This project was supported by the Center for Equine Health (UC Davis) and carried out in the UC Davis College of Agricultural \& Environmental Sciences; funds were provided by the State of California satellite wagering fund and contributions by private donors. Student support was given by the California Thoroughbred Foundation. Funds were also provided by the Agricultural Experiment Station at the University of California-Davis, an affiliate of the University of California Division of Agriculture and Natural Resources.

\section{Availability of data and materials}

The datasets used and/or analyzed during the current study are available from the corresponding author on reasonable request.

\section{Ethics approval and consent to participate}

Samples were collected from euthanized horses that were the property of the University of California Davis. Horses were euthanized for reasons other than this study; thus, IACUC exempted the tissue collection protocol.

\section{Consent for publication}

Not applicable.

\section{Competing interests}

The authors declare that they have no competing interests.

\section{Author details}

${ }^{1}$ Department of Animal Science, University of California Davis, 2251 Meyer Hall, One Shields Ave, Davis, CA 95616, USA. ²Department of Neurobiology, Physiology, and Behavior, University of California Davis, 195 Briggs Hall, One Shields Ave, Davis, CA 95616, USA. ${ }^{3}$ Department of Physiology and Membrane Biology, University of California Davis School of Medicine, 195 Briggs Hall, One Shields Ave, Davis, CA 95616, USA.
Received: 9 February 2020 Accepted: 15 September 2020

Published online: 23 September 2020

\section{References}

1. Tipton TE, Ray CS, Hand DR. Superficial digital flexor tendonitis in cutting horses: 19 cases (2007-2011). J Am Vet Med A. 2013;243:1162-5.

2. Thorpe CT, Glegg PD, Birch HL. A review of tendon injury: why is the equine superficial digital flexor tendon most at risk? Equine Vet J. 2010; 42(2):174-80.

3. Jacobson E, Dart AJ, Mondori T, Horadogoda N, Jeffcott LB, Little CB, Smith MM. Focal experimental injury leads to widespread gene expression and histologic changes in equine flexor tendons. PLoS One. 2015;10(4): e0122220.

4. Halper J. Connective tissue disorders in domestic animals. Adv Exp Med Biol. 2014;802:231-40.

5. Mienaltowski MJ, Birk DE. Structure, physiology, and biochemistry of collagens. Adv Exp Med Biol. 2014;802:5-29.

6. Dourte LM, Pathmanathan L, Mienaltowski MJ, Jawad AF, Birk DE, Soslowsky LJ. Mechanical, compositional, and structural properties of the mouse patellar tendon with changes in biglycan gene expression. J Orthop Res. 2013;31(9):1430-7.

7. Dunkman AA, Buckley MR, Mienaltowski MJ, Adams SM, Thomas SJ, Kumar A, Beason DP, lozzo RV, Birk DE, Soslowsky LJ. The injury response of aged tendons in the absence of biglycan and decorin. Matrix Biol. 2014;35:232-8.

8. Dunkman AA, Buckley MR, Mienaltowski MJ, Adams SM, Thomas SJ, Satchell L, Kumar A, Pathmanathan L, Beason DP, lozzo RV, Birk DE, Soslowsky LF. Decorin expression is important for age-related changes in tendon structure and mechanical properties. Matrix Biol. 2013;32:3-13.

9. Dunkman AA, Buckley MR, Mienaltowski MJ, Adams SM, Thomas SJ, Satchell L, Kumar A, Pathmanathan L, Beason DP, lozzo RV, Birk DE, Soslowsky LF. The tendon injury response is influenced by decorin and biglycan. Annu Rev Biomed Eng. 2014;42:619-30.

10. Mienaltowski MJ, Dunkman AA, Buckley MR, Beason DP, Adams SM, Birk DE, Soslowsky LJ. Injury response of geriatric mouse patellar tendons. J Orthop Res. 2016;34:1256-63.

11. Lechner BE, Lim JH, Mercado ML, Fallon JR. Developmental regulation of biglycan expression in muscle and tendon. Muscle Nerve. 2006;34(3):347-55

12. Robinson KA, Sun M, Barnum CE, Weiss SN, Huegel J, Shetye SS, Lin L, Saez D, Adams SM, lozzo RV, Soslowsky LJ, Birk DE. Decorin and biglycan are necessary for maintaining collagen fibril structure, fiber realignment, and mechanical properties of mature tendons. Matrix Biol. 2017;64:81-93.

13. Bi Y, Ehirchiou D, Kilts TM, Inkson CA, Embree MC, Sonoyama W, Li L, Leet Al, Seo BM, Zhang L, Shi S, Young MF. Identification of tendon stem/ progenitor cells and the role of the extracellular matrix in their niche. Nat Med. 2007;13:1219-27.

14. Frey H, Schroeder N, Manon-Jensen T, lozzo RV, Schaefer L. Biological interplay between proteoglycans and their innate immune receptors in inflammation. FEBS J. 2013;280(10):2165-79.

15. Ingraham JM, Hauck RM, Ehrlich HP. Is the tendon embryogenesis process resurrected during tendon healing? Plast Reconstr Surg. 2003;112(3):844-54.

16. Dyment NA, Liu CF, Kazemi N, Aschbacher-Smith L. The Paratenon contributes to Scleraxis-expressing cells during patellar tendon healing. PLoS One. 2013;8(3):e59944.

17. Jelinsky SA, Archambault J, Li L, Seeherman H. Tendon-selective genes identified from rat and human musculoskeletal tissues. J Orthop Res. 2010; 28(3):289-97.

18. Mienaltowski MJ, Adams SM, Birk DE. Regional differences in stem cell/ progenitor cell populations from the mouse Achilles tendon. Tissue Eng Part A. 2013;19(1-2):199-210.

19. Mienaltowski MJ, Cánovas A, Fates VA, Hampton AR, Pechanec MY, IslasTrejo A, Medrano JF. Transcriptome profiles of isolated murine Achilles tendon proper- and peritenon-derived progenitor cells. J Orthop Res. 2019; 37(6):1409-18.

20. Mienaltowski MJ, Adams SM, Birk DE. Tendon proper- and peritenonderived progenitor cells have unique tenogenic properties. Stem Cell Res Ther. 2014;5(4):86

21. Pechanec MY, Lee-Barthel A, Baar K, Mienaltowski MJ. Evaluation and optimization of a three-dimensional construct model for equine superficial digital flexor tendon. J Equine Vet Sci. 2018;71:90-7.

22. Paxton JZ, Grover LM, Baar K. Engineering an In vitro model of a functional ligament from bone to bone. Tissue Eng. 2010;16(11):3515-25. 
23. Kapacee Z, Yeung CY, Lu Y, Crabtree D, Holmes DF, Kadler KE. Synthesis of embryonic tendon-like tissue by human marrow stromal/mesenchymal stem cells requires a three-dimensional environment and transforming growth factor 33 . Matrix Biol. 2010;29(8):668-77.

24. Amenta AR, Yilmaz A, Bogdanovich S, McKechnie BA, Abedi M, Khurana TS, Fallon JR. Biglycan recruits utrophin to the sarcolemma and counters dystrophic pathology in mdx mice. PNAS. 2011;108:762-7.

25. Csont T, Gorbe A, Bereczki E, Szunyog A, Aypar E, Toth ME, Varga ZV, Csonka C, Fulop F, Santha M, Ferdinandy P. Biglycan protects cardiomyocytes against hypoxia/reoxygenation injury: role of nitric oxide. J Mol Cell Cardiol. 2010;48(4):649-52.

26. Reese SP, Underwood CJ, Weiss JA. Effects of decorin proteoglycan on fibrillogenesis, ultrastructure, and mechanics of type I collagen gels. Matrix Biol. 2013;32(7-8):414-23

27. Lee-Barthel A, Baar K, West DWD. Treatment of ligament constructs with exercise-conditioned serum: a translational tissue engineering model. JOVE-J Vis Exp. 2017;124:1-13.

28. Kapacee Z, Richardson SH, Lu Y, Starborg T, Holms DF, Baar K, Kadler KE. Tension is required for Fibripositor formation. Matrix Biol. 2008;27(4):371-5.

29. Calve S, Dennis RG, Kosnik PE II, Baar K, Grosh K, Arruda EM. Engineering of functional tendon. Tissue Eng. 2004;10(5/6):755-61.

30. Larkin LM, Calve S, Kostrominova TY, Arruda EM. Structure and functional evaluation of tendon - skeletal muscle constructs engineered in Vitro. Tissue Eng. 2006;12(11):3149-58.

31. Woessner JF Jr. The determination of hydroxyproline in tissue and protein samples containing small proportions of this imino acid. Arch Biochem Biophys. 1961;93:440-7.

32. Edwards CA, O'Brien WD Jr. Modified assay for determination of hydroxyproline in a tissue hydrolyzate. Clin Chim Acta. 1980;104(2):161-7.

33. Mushran SP, Agrawal MC, Prasad B. Mechanism of oxidation by chloramineT. Part I. Oxidation of a-hydroxy-acids. J Chem Soc. B 1971;Part I:1712-4.

34. Creemers $L B$, Jansen $D C$, van Veen-Reurings $A$, Van den Bos $T$, Everts $V$. Microassay for the assessment of low levels of hydroxyproline. Biotechniques. 1997;22:656-8.

35. Birk DE, Trelstad RL. Extracellular compartments in matrix morphogenesis: collagen fibril, bundle, and lamellar formation by corneal fibroblasts. J Cell Bio. 1984;99:2024-33.

36. Birk DE, Trelstad RL. Extracellular compartments in tendon morphogenesis: collagen fibril, bundle, and macroaggregate formation. J Cell Bio. 1986;103: 231-40.

37. Mienaltowski MJ, Huang L, Frisbie DD, Mcllwraith SW, Stromberg AJ, Bathke AC, MacLeod JN. Transcriptional profiling differences for articular cartilage and repair tissue in equine joint surface lesions. BMC Med Genet. 2009;2:60.

38. Mienaltowski MJ, Huang L, Stromberg AJ, MacLeod JN. Differential gene expression associated with postnatal equine articular cartilage maturation. BMC Musculoskelet Disord. 2008;9:149

39. Vandesompele J, De Preter K, Pattyn F, Poppe B, Van Roy N, De Paepe A, Speleman F. Accurate normalization of real-time quantitative RT-PCR data by geometric averaging of multiple internal control genes. Genome Biol. 2002;3:RESEARCH0034.

40. Scott EY, Mansour T, Bellone RR, Brown C, Mienaltowski MJ, Penedo MC, Ross PJ, Valberg SJ, Murray JD, Finno CJ. Identification of long non-coding RNA in the horse transcriptome. BMC Genomics. 2017:18(1):511.

41. Mansour TA, Scott EY, Finno CJ, Bellone RR, Mienaltowski MJ, Pendo MC, Ross PJ, Valberg SJ, Murray JD, Brown CT. Tissue resolved, gene structure refined equine transcriptome. BMC Genomics. 2017;18(1):103.

42. Ramakers C, Ruijter JM, Deprez RH, Moorman AF. Assumption-free analysis of quantitative real-time polymerase chain reaction (PCR) data. Neurosci Lett. 2003:339:62-6.

43. Schefe $\mathrm{JH}$, Lehmann KE, Buschmann IR, Unger T, Funke-Kaiser $H$ Quantitative real-time RT-PCR data analysis: current concepts and the novel "gene expression's CT difference" formula. J Mol Med (Berl). 2006;84:901-10.

44. Wilcoxon F. Individual comparisons by ranking methods. Biom Bull. 1945; 1(6):80-3.

45. Bland JM, Altman DG. One and two sided test of significance. BMJ. 1994; 309(6949):248.

46. Murphy R. On the use of one-sided statistical tests in biomedical research. Clin Exp Pharmacol Physiol. 2018;45(1):109-14.

47. Danielson KG, Baribault H, Holmes DF, Graham H, Kadler KE, lozzo RV. Targeted disruption of decorin leads to abnormal collagen fibril morphology and skin fragility. J Cell Bio. 1997;136(3):729-43.
48. Wadhwa S, Embree MC, Kilts T, Young MF, Ameye LG. Accelerated osteoarthritis in the temporomandibular joint of biglycan/fibromodulin double-deficient mice. Osteoarthr Cartilage. 2005;13(9):817-27.

49. Parisuthiman D, Mochida Y, Duarte WR, Yamauchi M. Biglycan modulates osteoblast differentiation and matrix mineralization. J Bone Miner Res. 2009; 20(10):1878-86

50. Han B, Li Q, Wang C, Patel P, Adams SM, Doyran B, Nia HT, Oftadeh R, Zhou S, Li CY, Liu XS, XL LU, Enomoto-Iwamoto M, Qin L, Mauck RL, lozzo RV, Birk $D E, H a n L$. Decorin regulates the aggrecan network integrity and biomechanical functions of cartilage extracellular matrix. ACS Nano. 2019; 13(10):11320-33.

51. Delalande A, Gosselin MP, Suwalski A, Guilmain W, Leduc C, Berchel M, Jaffres PA, Baril P, Midoux P, Pichon C. Enhanced Achilles tendon haling by fibromodulin gene transfer. Nanomedicine. 2015;11(7):1735-44.

52. Ye Y, Hu G, Guo F, Zhang W, Wang J, Chen A. Glycosaminoglycan chains of biglycan promote bone morphogenetic protein-4-induced osteoblast differentiation. Int J Mol Med. 2012;30(5):1075-80.

53. Berendsen AD, Fisher LW, Kilts TM, Owens RT, Robey PG, Gutkind JS, Young MF. Modulation of canonical Wnt signaling by the extracellular matrix component biglycan. Proc Natl Acad Sci U S A. 2011;108(41):17022-7.

54. Schonherr E, Levkau B, Schaefer L, Kresse H, Walsh K. Decorin affects endothelial cells by Akt-dependent and -independent pathways. Ann N Y Acad Sci. 2002;973:149-52.

55. Mohan RR, Tripathi R, Sharma A, Sinha PR, Giuliano EA, Hesemann NP, Chaurasia SS. Decorin antagonizes corneal fibroblast migration via caveolaemediated endocytosis of epidermal growth factor receptor. Exp Eye Res. 2019;180:200-7.

56. Geng Y, McQuillan D, Roughley PJ. SLRP interaction can protect collagen fibrils from cleavage by collagenases. Matrix Biol. 2006;25(8):484-91.

57. Meij JT, Carlson EC, Wang L, Liu CY, Jester JV, Birk DE, Kao WW. Targeted expression of a lumican transgene rescues corneal deficiencies in lumicannull mice. Mol Vis. 2007;13:2012-8.

58. Jiang W, Ting K, Lee S, Zara JN, Song R, Li C, Chen E, Zhang X, Zhao Z, Soo $C$, Zheng Z. Fibromodulin reduces scar size and increases scar tensile strength in normal and excessive-mechanical-loading porcine cutaneous wounds. J Cell Mol Med. 2017;22(4):2510-3.

59. Gaspar R, Pipicz M, Hawchar F, Kovacs D, Djirackor L, Gorbe A, Varga ZV Kiricsi M, Ptrovski G, Gacser A, Csonka C, Csont T. The cryoprotective effect of biglycan core protein involves toll-like receptor 4 signaling in cardiomyocytes. J Mol Cell Cardiol. 2016;99:138-50.

60. Barnette DN, Hulin A, Ahmed AS, Colige AC, Azhar M, Lincoln J. TGFß-Smad and MAPK signaling mediate scleraxis and proteoglycan expression in heart valves. J Mol Cell Cardiol. 2013;65:137-46.

61. Farhat YM, Al-Maliki AA, Chen T, Juneja SC, Schwarz EM, O'Kefe RJ, Awad HA. Gene expression analysis of the pleitrophic effects of TGF- $\beta 1$ in an in vitro model of flexor tendon healing. PLoS One. 2012;7(12):e51411.

62. Berendsen AD, Pinnow EL, Maeda A, et al. Biglycan modulates angiogenesis and bone formation during fracture healing. Matrix Biol. 2014;35:223-31.

63. Neill T, Painter $H$, Buraschi $S$, et al. Decorin antagonizes the angiogenic network. Concurrent inhibition of met, hypoxia inducible factor-1a and vascular endothelial growth factor a and induction of thrombospondin-1 and TIMP3. J Biol Chem. 2012;287:5492-506.

64. Korntner S, Lehner C, Gehwolf R, Wagner A, Grutz M, Kunkel N, Temfer H, Traweger A. Limiting angiogenesis to modulate scar formation. Adv Drug Deliv Rev. 2019;146:170-89.

65. DiPietro LA. Angiogenesis and scar formation in healing wounds. Curr Opin Rheumatol. 2013;25(1):87-91.

66. Cadby JA, Buehler E, Godbout C, van Weeren RP, Snedeker JG. Differences between the cell populations from the peritenon and the tendon core with regard to their potential implications in tendon repair. PLoS One. 2014;9(3): e92474.

67. Costa-Almeida R, Gonçalves Al, Gershovich P, Rodrigues MT, Reis RL, Gomes ME. Tendon stem cell niche. In: Turksen K, editor. Tissue engineering and stem cell niche. Cham: Springer; 2015. Stem Cell Niche.

68. Dyment NA, Hagiwara Y, Matthews BG, Li Y, Kalajzic I, Rowe DW. Lineage tracing of resident tendon progenitor cells during growth and natural healing. PLoS One. 2014;9(4):e96113.

\section{Publisher's Note}

Springer Nature remains neutral with regard to jurisdictional claims in published maps and institutional affiliations. 